\title{
A case method for Sales and Operations Planning: a learning experience from Germany
}

\author{
Luiz Felipe Scavarda ${ }^{a *}$, Bernd Hellingrath ${ }^{\mathrm{b}}$, Tobias Kreuter ${ }^{\mathrm{b}}$, Antonio Márcio Tavares Thoméa, \\ Marcelo Xavier Seeling ${ }^{\mathrm{a}}$, Jan-Hendrick Fischer ${ }^{\mathrm{b}}$, Raquel Mello ${ }^{\mathrm{b}}$ \\ aPontifícia Universidade Católica do Rio de Janeiro, Rio de Janeiro, RJ, Brasil \\ bWestfälische Wilhelms-Universität Münster, Münster, Alemanha \\ *If.scavarda@puc-rio.br
}

\begin{abstract}
Adequate preparation, learning, and training is required for Sales and Operations Planning (S\&OP) to aid organizations in achieving the full expected benefits from its implementation. This paper presents a case method for S\&OP and the learning experience of its application at the University of Münster (Germany). The "constructive alignment principle" was applied with a "team teaching" approach, involving an executive from the case company. Students improved their knowledge on S\&OP and their analytical skills by understanding the conceptual S\&OP building blocks and by learning how to deal with them to provide a solution for a case based on a real-life situation. The learning results were evaluated positively during the discipline's student evaluation of teaching (SET). The applied case method enhanced the student's motivation and engagement (e.g., higher preparation effort and class attendance), which were considered higher than in other disciplines with the traditional lecture-based education.
\end{abstract}

Keywords

Teaching case. Engineering education. Operations management. Supply chain. Production planning and control.

How to cite this article: Scavarda, L. F., Hellingrath, B., Kreuter, T., Thomé, A. M. T., Seeling, M. X., Fischer, J.-H., \& Mello, R. (2017). A case method for Sales and Operations Planning: a learning experience from Germany. Production, 27(spe), e20162199. http://dx.doi.org/10.1590/0103-6513.219916

\section{Introduction}

Sales and Operations Planning (S\&OP) emerged as a new and promising business concept. It unites different business plans into one integrated set of plans, aiming to balance supply and demand and to bridge the business and strategic plans with the operational plans of an organization (Thomé et al., 2012). Although different organizations have devoted efforts to introduce S\&OP in their operations, its successful implementation and use is still a challenge, as many companies fail in achieving the full-expected benefits from its adoption (Godsell et al., 2010; Rexhausen et al., 2012; Wagner et al., 2014). The lack of a complete comprehension of the main building blocks of S\&OP is one of the main reasons hindering a successful implementation, preventing the realization of S\&OP's full potential benefits. Therefore, S\&OP stakeholders must improve their understanding of this business concept and of its different implementation needs (e.g., process view, soft issues management, new functionalities, goal alignment, commitment, plan integration) and should be appropriately trained (Kjellsdotter lvert \& Jonsson, 2014; Wagner et al., 2014; Goh \& Eldridge, 2015).

This scenario motivated the authors of this paper to develop a teaching case method for S\&OP to help students understanding its main building blocks towards successful implementations in the future. The case method (also referred as case-based learning, case study teaching, and teaching case) is an instructional technique that aids students to develop critical thinking and decision-making skills, by challenging them to analyze problems in real-world situations offered in cases. Students should draw inferences based on limited information, and make decisions on uncertain, ambiguous and conflicting issues that simulate a real-world, 
professional context. The case method is structured and provides learning goals for tasks, which the students should perform (Kim et al., 2006). It reduces the distance between teaching methods and practical (reality) contexts. This approach has been used for decades in Business Management lectures (e.g., Harvard Business School) and also been adopted in classrooms of different disciplines such as information systems (Hackney et al., 2003), education (Levin, 1995), mathematics (Barnett, 1998), medicine, and engineering (Kim et al., 2006). One may distinguish the teaching case method from a case study. Case study refers to a well-known research method that is important to develop new theories and insights. Scholars adopt case studies for different kinds of research purposes as exploration, theory building, theory testing, and theory extension/refinement. It enhances not only theory, but also the researchers involved in its conduction, providing useful results for practitioners (Voss et al., 2002). While case studies are more connected to research and theory development, teaching case methods are more related to instructing, coaching and training that can attend different educational levels (schooling, undergraduate / graduate degrees), which is the target audience of this paper. Different authors in the literature report positive results of the use of case methods in learning (e.g., Lundeberg \& Yadav, 2006; Prince \& Felder, 2007; Spooren et al., 2013).

The case method is frequently compared with problem-based learning. Nevertheless, the differences between them are not always clearly described (Thistlethwaite et al., 2012). Both contrast traditional lecturebased educational approaches and share some commonalities. For instance, in both approaches students are presented with a problem, having time to struggle, define, and resolve the problem, leading to more than just a conduction of simple analyses (Srinivasan et al., 2007). The learning processes generally occur in groups of students, rather than in lectures conducted by teachers. However, there are some differences between the two approaches. Problem-based learning focuses on the discovery process of the students, towards stimulating problem solving, independent learning, teamwork, and critical thinking, where facilitators play a minimal role and do not guide the case discussion (Srinivasan et al., 2007). Students face a challenging problem without previous study preparation in the field of the problem. In turn, the case method is more structured than the problem-based learning (i.e., it adopts a guided inquiry method with defined learning outcomes). It requires a more advanced preparation beforehand and students may raise questions to experts during the session. Moreover, facilitators play a more important role in the case method approach as well and, for instance, correct improper assumptions of the students or bring them back to the main learning goal if they begin to explore tangents (e.g., through guiding questions) (Srinivasan et al., 2007; Thistlethwaite et al., 2012).

Within this context, the goal of this paper is twofold: (i) to present a teaching case method for S\&OP, addressing the need for training stakeholders in the S\&OP main building blocks, to facilitate successful implementations in real-life cases and (2) to present the learning experience of its introduction in a discipline of a Master of Science program at the University of Münster (Germany).

The paper is structured in five main sections, with this one being the introduction. Section 2 provides the main conceptual building blocks for S\&OP. Section 3 presents the methodology, followed by a section describing the teaching case itself. Section 5 presents the authors final remarks. The teaching guide is offered in Appendix A.

\section{Building blocks for S\&OP}

The American Production and Inventory Control Society (APICS) provides a comprehensive definition of S\&OP as follows:

[...] a process to develop tactical plans that provide management the ability to strategically direct its businesses to achieve competitive advantage on a continuous basis by integrating customer-focused marketing plans for new and existing products with the management of the supply chain. The process brings together all the plans for the business (sales, marketing, development, manufacturing, sourcing, and financial) into one integrated set of plans. It is performed at least once a month and is reviewed by management at an aggregate (product family) level. The process must reconcile all supply, demand, and new product plans at both the detail and aggregate levels and tie to the business plan. It is the definitive statement of the company's plans for the near to intermediate term covering a horizon sufficient to plan for resources and support the annual business planning process. Executed properly, the sales and operation planning process link the strategic plans for the business with its execution and reviews performance measures for continuous improvement. (Cox \& Blackstone, 2002, p. 154).

Although S\&OP has become a relevant topic, the literature still offers few frameworks and models for S\&OP. Thomé et al. (2012) established a framework based on a research synthesis (considering both academic and grey literatures) with the S\&OP key elements and dimensions, as defined by APICS. It consists of four elements 
(i.e., context, inputs, structure and processes and outcomes / results) that combined aim to bridge business or strategy plans to operations plans. Figure 1 presents the framework.

Reading the framework from top-down, it depicts the merging of strategic and business plans with operations, situated at the tactical level of the production planning hierarchy. From left to right, the building blocks starts with the environment in which S\&OP is immersed: the contextual variables. As S\&OP is a management practice engrained into operations management practice contingency research (Sousa \& Voss, 2008), the process changes according to varying contextual variables. Examples are country, industry, manufacturing strategy, hierarchical planning. Within this context, the S\&OP meetings require inputs, usually under the form of sectorial plans, restrictions, budgets and goals. The middle block of structure and processes details the S\&OP management practice: meetings regularity, participants, agenda, organizational and technological aspects. The middle block drives the basic outcome preconized in the APICS definition: an integrated set of plans, which leads to profit optimization and feedback to the inputs for the next S\&OP meetings.

The framework is based in previous S\&OP maturity models, described in Thomé et al. (2012) and Mendes Junior et al. (2016). However, it differs from maturity models in important ways. First, it is an analytical, and not a prescriptive tool. It serves as a road map to ascertain and describe processes, but it does not prescribe how they should be implemented. Maturity models classify and define a road map for improvement, in a prescriptive manner. Second, it provides a visual representation of building blocks and the relationships between the blocks, which is not usual in the representation of maturity models. Three maturity models were particularly relevant for the construction of the framework: the Aberdeen Group (Elbaum, 2004), Lapide (2005), and Grimson \& Pyke (2007). Aberdeen uses six categories (process, organization, resource effectiveness, IT architecture, decisionmaking and collaboration) to classify companies in each category as laggard, average and best in class. Lapide (2005) uses the categories of meetings, processes and technology to classify companies in a four-stage maturity model. The stages are marginal, rudimentary, classic and ideal. Grimson \& Pyke (2007) expand upon these models, proposing the categories of meetings and collaboration, organization, measurements, information technology and plan integration. Thomé et al. (2012) framework is a synthesis regrouping the dimensions of Grimson and Pyke's categories under the middle box of processes and structures, except for integration of plans, which is emphasized as an outcome of the process. Consistent with Grimson \& Pyke (2007), the end-result under the framework is profit optimization. The elements of vertical alignment from the business plan to operations and the S\&OP antecedents of context and inputs complete the framework of Figure 1, conferring to it a holistic approach embracing all aspects of S\&OP according to the APICS definition (Cox \& Blackstone, 2002).

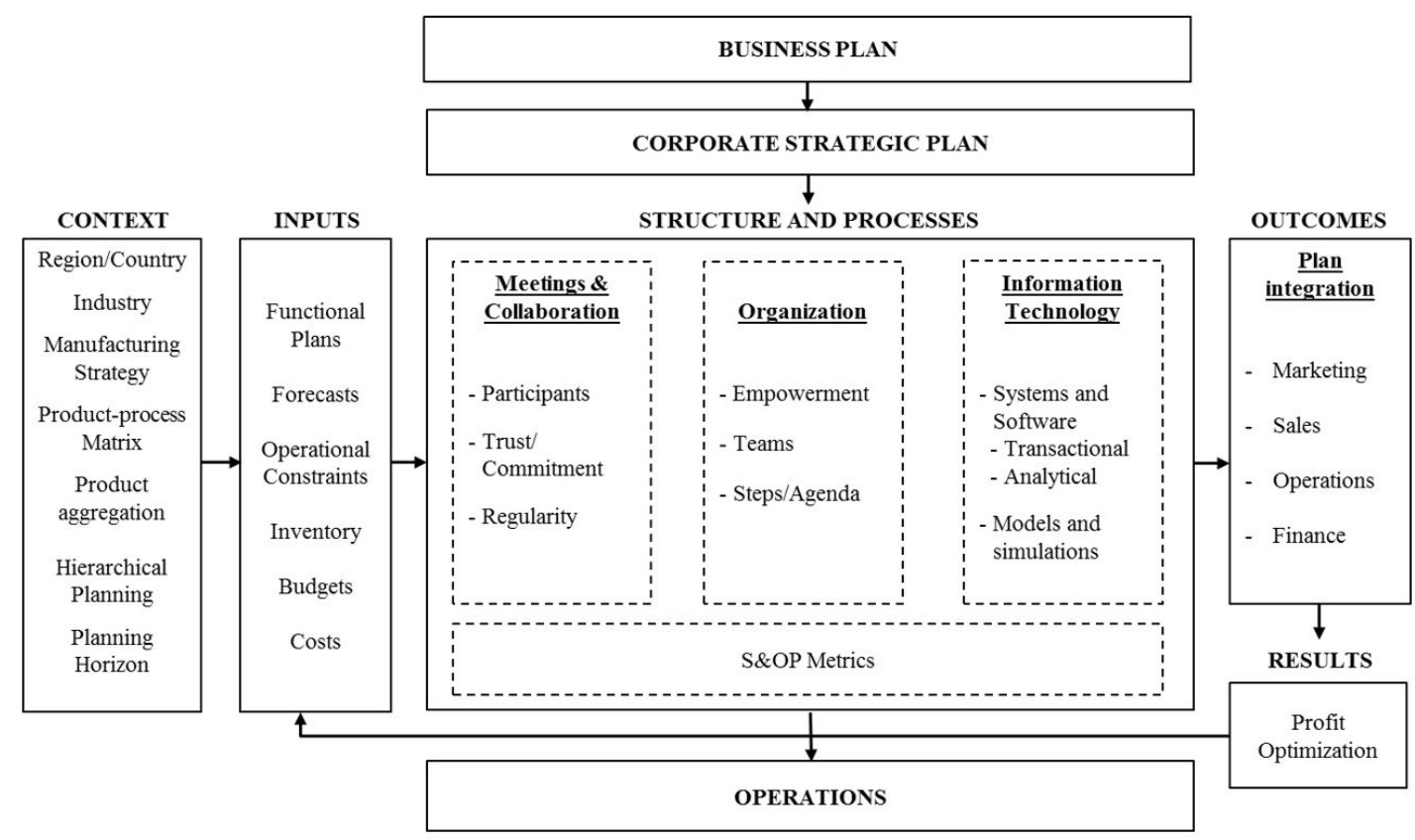

Figure 1. The S\&OP Framework. Source: Thomé et al. (2012). 
There are some more specific frameworks, dealing with some dimensions of the S\&OP process that are equally proposed in the literature. They are at least partly based on Thomé et al. (2012) framework. Tuomikangas \& Kaipia (2014) put forward a framework, which specifically focusses on coordination for S\&OP (see Figure 2). It comprises in the vertical axis the dimensions of strategic alignment and performance management. The horizontal axis contemplates the processes, tools and data, organization, culture and leadership of S\&OP.

Noroozi \& Wikner (2017) suggests an integrative framework that extends Thomé et al. (2012) framework into the supply chain. Figure 3 depicts the framework.

Noroozi \& Wikner (2017) integrative framework shows the participants from the supply chain, a feature only described previously on the more advanced stages of S\&OP maturity models (e.g., Lapide, 2005; Grimson \& Pyke, 2007). Issues related to horizontal and vertical integration are equally reviewed in the framework, as well as the balance of supply and demand. The integration issues are reviewed under "inputs" and under "structure and processes" in Thomé et al. (2012) and under "structure" in Tuomikangas \& Kaipia (2014). Supply chain tiers and Risk/scenario management is added as a contribution to previous frameworks.

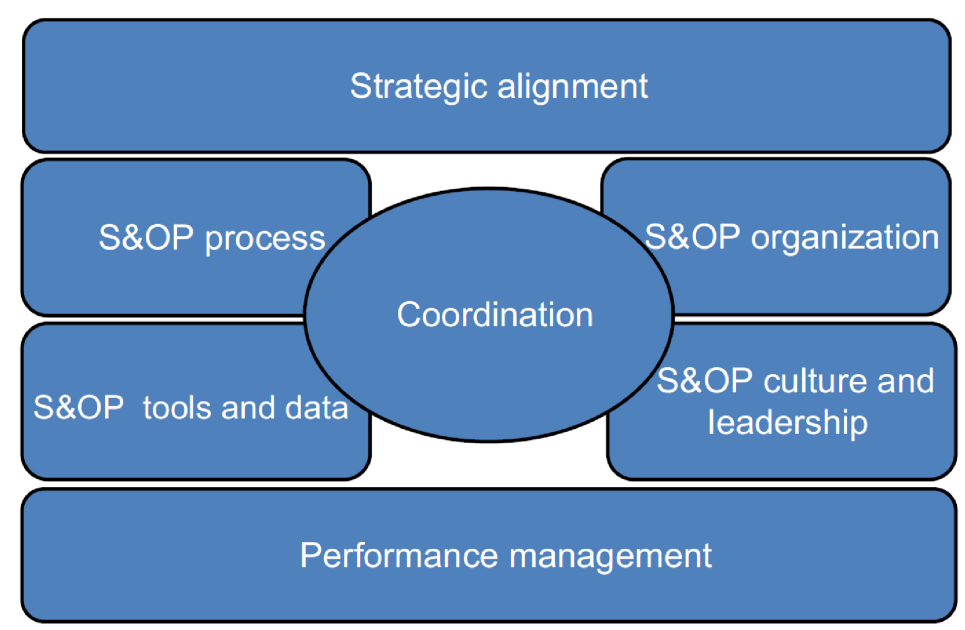

Figure 2. Tuomikangas \& Kaipia (2014) S\&OP coordination framework.

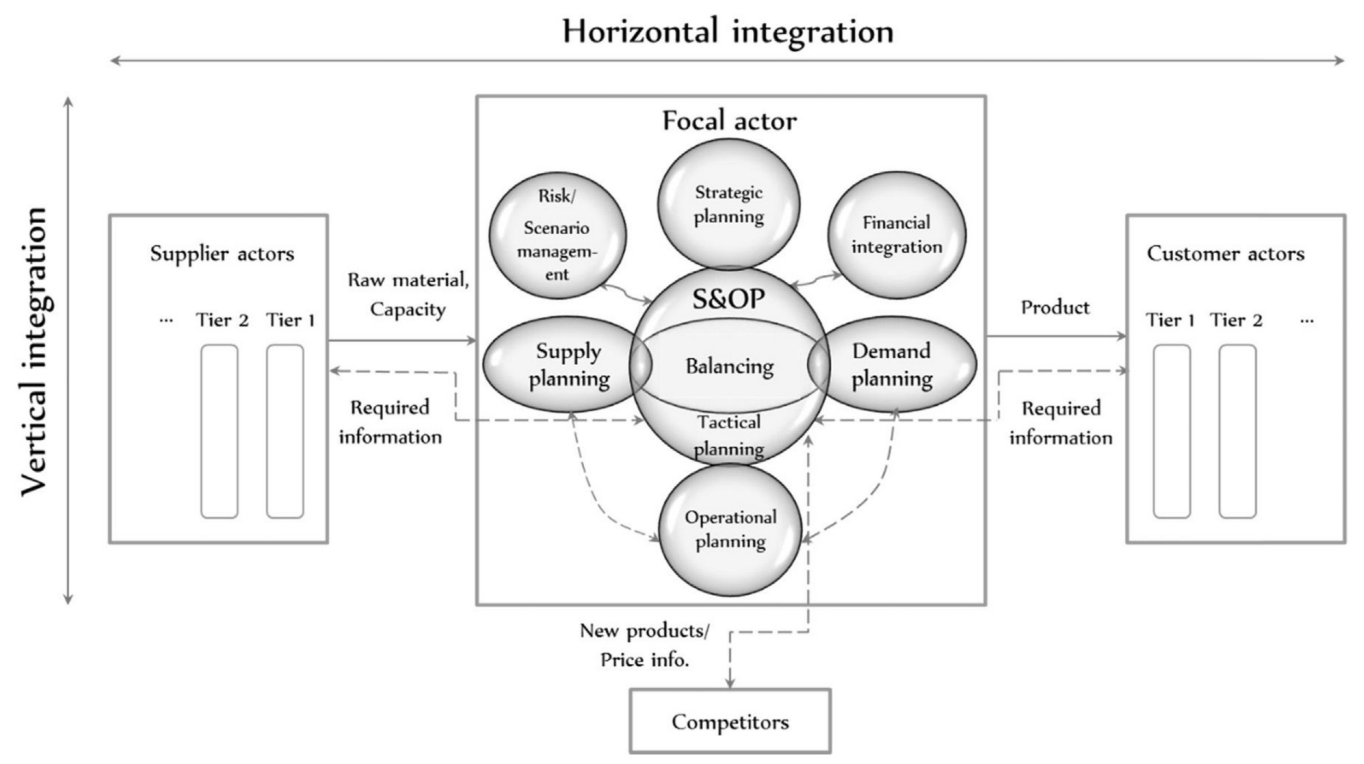

Figure 3. Noroozi \& Wikner (2017) integrative S\&OP framework. 
In addition to these two frameworks described in more detail, Thomé et al. (2012) framework served as a basis for the S\&OP frameworks from Thomé et al. (2014), Hollmann et al. (2015), Hulthen et al. (2016), and to propose S\&OP analytical contingency frameworks (Kjellsdotter lvert et al., 2015b). It was used for the conduction of empirical studies on S\&OP (e.g., Kjellsdotter lvert et al., 2015a) as well. The application of the framework in a teaching case method is a contribution of this paper. Thomé et al. (2012) framework was chosen because it fits the requirements of the case study in four main aspects. First, it describes the constitutive elements of a process, with a number of setup and parameters (Kjellsdotter lvert et al., 2015b), with inputs, activities, outcomes and feedback loops. Second, it is holistic, as "[...] it considers S\&OP as a whole, not as a partial process or from a single viewpoint, and is especially suitable for detailed analyses in the structure of S\&OP." (Kjellsdotter lvert et al., 2015b, p. 750). Third, it describes S\&OP as a generic process, not restricted to a given type of industry, product or service (Noroozi \& Wikner, 2017). Fourth, it provides a visual synthesis of the S\&OP building blocks in accordance with the APICS's comprehensive definition and depicts the relationships among the S\&OP concepts.

Table 1 presents an adaptation of the main conceptual building blocks for S\&OP used for the conception of the teaching case method.

\section{Methodology}

The case method development and application adopted a "team teaching" approach (i.e., shifting the role of instruction from the individual to a team, Buckley, 1999), by combining two well-known models labelled by Baeten \& Simons (2014) as "teaming model" and "assistant teaching model". In the "teaming model", three professors from different universities and fields (i.e., Industrial Engineering and Information Systems) cooperated by equitably sharing responsibilities and discipline's tasks, from planning to evaluation. These professors had a group of teaching assistants who assisted in organizing the conduction of the discipline and supported the students inside and outside the classroom. This required a detailed planning of the collaboration among assistants and professors before the start of the course. An executive from the company that offered the real-life case was also involved in the planning process. This section initially presents the development of the teaching case method. The application a discipline at the University of Münster is offered next.

Table 1. Building blocks for S\&OP.

\begin{tabular}{|c|c|c|c|c|}
\hline & $\begin{array}{l}\text { Context: } \\
\text { In which context is S\&OP } \\
\text { applied? How are they related } \\
\text { to S\&OP and what are their } \\
\text { influence? }\end{array}$ & $\begin{array}{l}\text { Inputs: } \\
\text { What are the main data used? } \\
\text { What are the data sources, } \\
\text { including information } \\
\text { system, when available? Who } \\
\text { is the responsible for the } \\
\text { data and the related business } \\
\text { functional area? }\end{array}$ & $\begin{array}{l}\text { Outcomes / Results: } \\
\text { What compounds plan } \\
\text { integration? What are the } \\
\text { main potential results (e.g., } \\
\text { financial, market-related and } \\
\text { operational) and the ones } \\
\text { achieved in practice? }\end{array}$ & $\begin{array}{l}\text { Elements of other S\&OP } \\
\text { models / frameworks: } \\
\text { What are the elements of } \\
\text { the other S\&OP models / } \\
\text { frameworks? How are these } \\
\text { elements organized? }\end{array}$ \\
\hline $\begin{array}{c}\text { Main } \\
\text { elements }\end{array}$ & $\begin{array}{l}\text { Meetings and collaboration: } \\
\text { Who are the participants } \\
\text { involved (e.g., functional areas, } \\
\text { hierarchal level, business units, } \\
\text { subsidiaries, supply chain } \\
\text { members). Who attends the } \\
\text { meetings? What are their role, } \\
\text { commitment, and frequency } \\
\text { attending? }\end{array}$ & $\begin{array}{l}\text { Organization: } \\
\text { Are S\&OP teams formally } \\
\text { stablished with specific roles } \\
\text { for the members? Is there any } \\
\text { team hierarchy / structure } \\
\text { (e.g., moderators, responsible } \\
\text { for the setting, any manager } \\
\text { leading the team)? What is the } \\
\text { role of empowerment and how } \\
\text { is it stablished? What are the } \\
\text { main S\&OP steps and agenda? } \\
\text { What are the requirements, } \\
\text { decisions and results of each } \\
\text { step? }\end{array}$ & $\begin{array}{l}\text { Information technology: } \\
\text { What are the requirements } \\
\text { for an information system (IS) } \\
\text { for S\&OP? What are the main } \\
\text { software solutions and their } \\
\text { respective interfaces with other } \\
\text { IS? Which are the factors for a } \\
\text { successful implementation of } \\
\text { an IS for S\&OP? How to deal } \\
\text { with soft aspects as individual } \\
\text { knowledge and understanding } \\
\text { of IS and functionalities? }\end{array}$ & $\begin{array}{l}\text { S\&OP metrics: } \\
\text { What are the requirements and } \\
\text { problem areas for performance } \\
\text { measurement in S\&OP? What } \\
\text { are the key performance } \\
\text { indicators and performance } \\
\text { measurement systems used } \\
\text { for S\&OP? How are they } \\
\text { used, by whom and with what } \\
\text { objective? What is needed for } \\
\text { the development of a S\&OP } \\
\text { dashboard? What does it } \\
\text { contain? }\end{array}$ \\
\hline $\begin{array}{l}\text { Related } \\
\text { aspects }\end{array}$ & $\begin{array}{l}\text { Vertical alignment: } \\
\text { How does S\&OP build bridges } \\
\text { between business / strategic } \\
\text { plans and operations plans? }\end{array}$ & $\begin{array}{l}\text { Maturity Models: } \\
\text { What are the existing maturity } \\
\text { models for S\&OP? What are } \\
\text { their levels and dimensions? } \\
\text { How can a higher maturity } \\
\text { level be achieved? }\end{array}$ & $\begin{array}{l}\text { S\&OP and other supply chain } \\
\text { integration (SCI) practices: } \\
\text { How can S\&OP be compared } \\
\text { with other } \mathrm{SCl} \text { practices (e.g., } \\
\text { CPFR, DMI)? Where does } \\
\text { S\&OP fit in the production } \\
\text { planning blocks (e.g., MRP, } \\
\text { MRP 11)? }\end{array}$ & $\begin{array}{l}\text { Empirical studies / } \\
\text { implementation: } \\
\text { What has been done in the } \\
\text { industry? What are the main } \\
\text { challenges and benefits } \\
\text { encountered by companies } \\
\text { with S\&OP implementation? }\end{array}$ \\
\hline
\end{tabular}

Note: CPFR-Collaborative Planning, Forecasting \& Replenishment; DMl-Design-Manufacturing Integration; MRP-Material Requirement Planning. Source: Adapted from Thomé et al. (2012). 


\subsection{Case method development}

The teaching case method was based on a real-world S\&OP context. It was developed in close collaboration with an executive from a company that offered the real-life insights, which served as the basis for the case scenario. The name of the company, its geographic locations, and numbers were changed due to confidentiality reasons. The names of the executives were removed for the same reason.

The case method was developed by following the reference guideline from Farhoomand (2004) and aimed to serve the following purposes: (i) bringing a neutral context, without "taking sides" that could influence students on one or another direction with bias, leaving them to conclude and make decisions of specific arguments and actions provided in the case based on their understanding of the facts; (ii) being sufficiently broad and rich in terms of contextual nuances to challenge students in a non-easy and evident context, making them to decide what is a relevant fact and what is not; (iii) providing a real-life scenario to challenge students to move to higher orders of learning by prompting them to ask "how" the issues are related to one another and "why" things happen the way they did, and by this forcing them to put related facts together into a coherent, articulated plan of action; and (iv) avoiding the inclusion of analysis in the text, as this is a task reserved for the students. The role of students in the decision making process about the alternatives presented in the case scenario should be paramount. The students themselves should decide on the merits of any specific argument based on their understanding of the facts and on their theoretical background on the subject. The end-result should be a proposal for action to solve the problems of the presented scenario with its dilemmas and challenges.

\subsection{Case method application approach}

The discipline, in which the case method was applied, was part of a Master of Science program with students from different countries. It was designed, applying the constructive alignment principle (Biggs, 2003; Biggs \& Tang, 2011). This principle represents a system view on the discipline, embracing the purposeful design and relation between the discipline's learning outcomes, activities, assessments, as well as its evaluation, which should support the learning improvement (Edström, 2008). The learning outcome of this discipline aimed to provide students with the knowledge of how to overcome practical challenges by applying the main building blocks of S\&OP in a real-life situation, contributing to improve their analytical and critical-thinking skills. To achieve this, the discipline was subdivided into two phases: a theoretical and a practical one. An overview of its different components resulting from the learning outcome is provided in Figure 4.

The theoretical phase aimed to develop the students' comprehension of the main S\&OP building blocks and their related aspects (see Table 1) and intended to serve as an enabler for the second phase. Herein, learning activities were established and consisted of (i) attending key-note classes in the beginning of the semester provided by the three professors, (ii) reading the papers from the academic and gray literature on the topic (both the ones recommended by the professors and new sources selected by the students), (iii) discussing evolutions with the professors and teaching assistants in regular meetings, (iv) writing an essay about an individual topic and (v) conducting an oral presentation about the essay's topic. For the individual essay, each student could choose one of the provided S\&OP-related topics, building upon the academic literature in this area. In order to

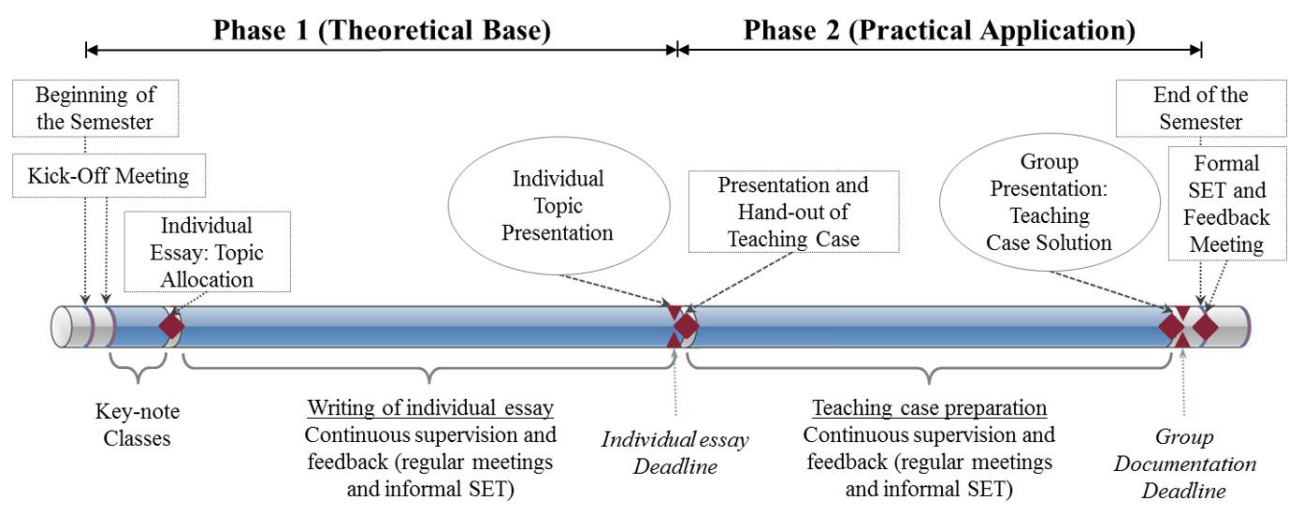

Figure 4. Overview of the adopted constructive alignment principle. 
ensure that the students would acquire a comprehensive knowledge, each individual topic was related to one of the building blocks of S\&OP, as presented in Section 2. While writing the essay, the students were supervised by the teaching assistants and regular feedback sessions were provided, in which questions were answered and interrelations between the different topics were drawn. This continuous feedback was done in groups, so that the students could acquire knowledge form their classmates and were able to apply their own knowledge by drawing connections to their individual topic. Assessments during the first phase consisted of the individual essays and students' presentations of their topics. Oral presentations were given to the whole class and followed by a discussion round with all students. By this, the knowledge of the different building blocks should be shared, aiming to level the student's understanding of S\&OP before the beginning of phase 2 .

The practical phase built upon the results of phase 1. The knowledge obtained by the students was applied in a real-life situation towards improving their analytical and critical-thinking skills. The learning activities consisted of the S\&OP teaching case itself (see Section 4), starting with its presentation to the students. The supervisors informed the participants about the general settings and the guidelines for the teaching case. An executive of the company that inspired the case was present and provided the case scenario and additional insights, followed by a Q\&A section. The students assumed the role of a consultancy company and should develop a solution regarding the case-specific problems and ultimately present their suggestions to the company's board of directors, a role assumed by the professors, the company executive and the teaching assistants. The class was divided into different groups, each presenting one consultancy company that should independently find a solution for the teaching case. During the preparation of the solution, the teaching assistants supervised each group and guidelines were given, whenever necessary. The students had to record their proceedings in a written documentation, in which they should reflect the organization within their group, present the responsibilities of the different group members, describe the decision-making process, and ultimately explain the reasoning for their proposed solution. At the end of the discipline, each group presented their case solution to the company's board of directors. The groups presented their case solutions independently, so that their results would not be influenced by the ones from other groups. After presenting their solution, the company's board asked critical questions and the students needed to defend their solution. Students' assessments were based on the applicability of their solution, their problem-solving approach and their provided project plan.

The discipline evaluation is an important component of the adopted constructive alignment principle. The University of Münster has a formal "student evaluation of teaching" (SET), normally conducted at the end of the semester, aiming to sustain learning improvement. As the discipline counted with a novel teaching approach for the Master program, additional and more frequent evaluation steps and procedures were conducted. The discipline embraced formal and informal evaluations at different times during the semester. A formal, anonymized, written, and individual evaluation was conducted at the end of the semester, using a questionnaire that consisted of closed-ended and open-ended questions. Consistent with Spooren et al. (2007), the closed-ended questions were rated on a seven-point Likert-type scale ( $1=$ "disagree completely" to $7=$ "agree completely"), with several dimensions to evaluate and measure teaching quality offered in the discipline. Following Spooren et al. (2013), open-ended questions complemented the SET with more specific comments from the students regarding the discipline, the case method, and the teaching quality. This was important to address specificities of the discipline itself, as the quality and synchronization of the "team teaching" approach, combining the "teaming model" and the "assistant teaching model", what was not included in the University's standard SET. Additionally, informal, oral, and group evaluations were conducted during each phase, involving students, teaching assistants, and professors. Herein, the experiences from the course, as well as the students' learning outcomes and activities were reflected. A final feedback meeting at the end of the discipline was organized and served the following purposes. On the one hand, a reflection on the different groups' solutions was presented, alternative solutions were discussed and lessons learned during the course were evaluated. On the other hand, the students discussed their learning experience regarding the discipline and its novel approach, and compared it with teaching forms in normal classes.

Next, the paper offers the description of the case used in the discipline.

\section{Teaching case method (Global-Enterprises lnc.)}

Global-Enterprises Inc. has just hired a new CEO with the mission of primarily growing its business and increasing its share value, putting the company back on track and leading it to a bright future. The company's share value has decreased in the past two years. The trend concerns the board as shareholders who are dissatisfied may decide to invest in more attractive businesses. In addition, the current share value puts the corporation in a vulnerable position with risk of being bought by a competitor in an aggressive movement in the Wall Street stock market. 
During the first months, the CEO performed a deep dive in the company business and financial figures. He identified the following:

- The service level is lower than market average in this industry (86\% line-fill, 88\% on-time-deliveries);

- The inventory level is very high in comparison with the sales and above the budget ( 2.7 turns per year, approximately 135 days on-hand);

- The company generates enough cash flow to run the business, but not to invest;

- The return-on-assets (ROA) is low, below the industry average;

- The company is profitable and the margins are healthy, but they are decreasing due to growing operations costs (2.7\% decrease since previous year and below budget);

- The frequent new product launches are not bringing the planned revenues and are indicative that the company has lost market share, not yet quantified;

- The supply is very complex: half the portfolio of products is manufactured in company owned plants in different countries, the "global manufacturing excellence centers", and the other half is sourced from many suppliers from different countries;

- Although the two main consumer product lines do not have production synergies, they have distribution synergies. They are profitable and promising and they contribute to balance the company's results, as never both businesses are in a bad moment at the same time globally.

The CEO knows the traditional approach that consultancy firms implement when the bottom line is lower than planned and a shock management is needed to produce a turnaround: cut costs, reengineer and right size the organization. That approach is mandatory when the company is sinking but this corporation is profitable, it has recognized brands, and great people. In this present case, it seems that operational problems, lack of internal coordination, communication gaps and poor planning processes are preventing the business from being successful. In addition, the company needs to unleash growth by investing in Research and Development (R\&D) and Marketing to boost new launches. The Sales force needs better service levels to support the sales growth plans and expand the customer basis worldwide.

In his former company, the CEO experienced an S\&OP implementation project from the beginning. When he left the company, a standard S\&OP process was running periodically. Although the process was not completely mature yet, he was able to verify fast improvements in the company and promising preliminary results. The CEO does believe it is possible to improve the service level, diminish the inventory and increase the working capital and profit, all at the same time. Therefore, he decided to hire a German consultancy firm, with high market reputation and a history of recent successful S\&OP implementations, to analyze his case and help his corporation to solve its problems.

\subsection{The company}

Global-Enterprises Inc. is a multinational corporation headquartered in Dallas (USA), where the company started in the early 1970's. Previously called Texas Tools, it grew along four decades and became a global corporation by purchasing other companies from the same business segment and sometimes from completely different industries. In the mid 1980's, Texas Tools bought a company with subsidiaries in other countries, which made the enterprise expand its operations and launch a step-by-step transition from an American based company to a multinational corporation. It is still an ongoing process after all these years and occasionally a "what is good for USA should be good for the world" mindset or simply a misunderstanding of other countries' realities and cultures generate noise in the subsidiaries' operations. Today it is present in more than 30 countries and employs 12,000 people worldwide. The sales are healthy bringing in revenues of around US\$ 5 Billion, spread in four geographic regions but highly concentrated in USA and Canada, who together contribute with 65\% of the total revenue. The remaining comes from Europe (26\%), Asia-Pacific (6\%) and Latin America (3\%). The company sees opportunities to expand sales in Asia-Pacific, especially in China and India, and in Latin America, especially Brazil and Mexico. USA's growth has been small in the past years and Europe's growth has been flat, close to zero. Around 600 people work in the main office building in Dallas, controlling and auditing (compliance) the subsidiaries in 32 countries, consolidating results, defining the global strategies and setting the company goals. Another office is kept in New York just for market relations (communication with the main 
shareholders and key professionals in Wall Street) and for periodic meetings among the board members and the CEO. Besides the new CEO, there is a COO responsible for Operations worldwide and for Global Sourcing, a CFO overlooking Finance, a ClO managing information technology, a Global Marketing and Sales Vice-President and a Global R\&D and Quality Vice-President.

Global-Enterprises Inc. manufactures and commercializes globally a wide variety of consumer goods of well-known brands. Along the years, the company has concentrated its focus on the most profitable and promising businesses. Most of the smaller businesses with low performance from different segments were sold. The company is organized in two divisions according to its main product lines (i.e., hand tools and office products), maintaining relationships with customers from several market channels: distributors, wholesalers, specialty supply centers, mass merchandisers and other retailers (e.g., smaller retail chains and individual stores). The hand tools business exists since the company foundation and it expanded by acquiring other manufacturers in USA and later in UK, Brazil, China, Mexico, and Germany. In 2015 this business contributed with US\$2.5 Billion in revenues and $42 \%$ margin. The company has invested in technology and built a complete portfolio of products (around 8,000 Stock-Keeping-Units/SKUs) of recognized brands, launching new products year over year. The office product business brought in 2015 revenues of 2.3 Billion, 38\% margin, with around 2,000 SKUs. This business was one of those opportunities that ended up in a great success, with the company being today one of the top five in this industry globally. Both hand tools and office product businesses had similar margin decreases, reflecting in a $2.7 \%$ loss in the total business average margin, when compared to previous year. The negative trend continues and concerns Sales, Marketing, and Finance professionals.

As part of the strategic plan being built to revamp the company with the arrival of the new CEO, the corporation has reviewed its values, mission and vision as follows:

- Mission: "Our mission is delighting our customers with excellent tools and office products that allow them to express themselves and build a better world";

- Vision: "Global-Enterprises will become one of the top three global players in the businesses and markets we participate with our high quality innovative products and recognized brands";

- Values: (i) "Our enterprise must be profitable to be healthy and remunerate our shareholders.", (ii) "We highly value and care about all our stakeholders: our employees, our shareholders, our customers, our suppliers and the communities we are inserted in worldwide.", (iii) "We do business with ethics, respecting sustainability and abiding strictly to the law in all the countries in which we operate.", and (iv) "We provide innovative high quality products to our customers."

\subsection{Operations and functional areas}

\subsubsection{Sales}

The sales force complains that they could sell more if they had better service levels. In their perspective, the company needs more inventory to attend the demand that is always changing in this dynamic and competitive environment. They believe that people from the other areas in the company are immersed in their offices and plants and do not understand the customers' needs, their ultimate bosses, neither they know how hard the competition is in the market. Sales representatives consider that their primary responsibilities are first bringing in more orders, what solely happens in the field, talking to the customers, far from all the bureaucracy at the office, and second delivering the financial budget. They know they have to provide a sales forecast but it is very hard to anticipate exactly what the customers will demand. From their point of view, the company manufacturing plants and key suppliers should be more flexible to respond to demand changes that happen all the time and cannot be controlled nor anticipated.

Another good measure to help to increase sales frequently suggested by the sales representatives is relaxing the terms of payments, as everybody knows there is a crisis out there and the customers need friendlier conditions to pay nowadays. Sales force argues the competitors work with higher inventories, provide better services and offer softer terms of payment. They believe they do an excellent job considering these limitations. The sales force's variable salaries and bonuses depend on the sales orders brought to the company, regardless of the forecast accuracy, of the orders effectively received by the customers and the returns.

The Sales force does not have much contact with the Operations teams. In fact, the contacts between these areas are rare in all hierarchical levels of the organization. The Sales force perception about Operations is that 
they do not understand the customer needs and the market dynamism and they keep asking for too much information, there is no way they can predict months in advance. Part of their frustration is that, despite of all the information they struggle to provide, service level continues poor.

They also think Finance is too much focused on the budget prepared in the middle of the previous year, so far from current reality. Every month Finance scrutinizes their results in detail by product line, the margin changes and the total revenue, as they were their bosses, requesting information and explanations to prepare their reports. Fortunately, they have brought the orders, many times even more than originally planned, although not necessarily according to the forecast. But that is how it is: according to sales, the market decides what it wants to buy and the company must have inventory to provide a good service.

\subsubsection{Marketing}

The Marketing area is organized internally by the two product lines (hand tools and office products), reproducing the company's organizational division. There is good interaction with R\&D, which encompasses product engineering. The products developed are usually of good quality, innovative, and match market needs, trends and opportunities. The brands are recognized in USA, Canada, Mexico and Western Europe but there are still opportunities to increase the awareness in the rest of Latin America and Asia-Pacific regions. The portfolio of products is complete and in general fits well the global needs.

From the marketing perspective, their main problem has been the execution of the new launches. The Marketing teams believe Operations, encompassing Process Engineering, Manufacturing, Foreign-Trade, Supply, Logistics and Sourcing areas, should be more responsive and less bureaucratic, allowing the company to shorten and accelerate new launch projects. In their opinion, the long lead-times, project delays, and lack of products affect the timing and the result of the new launches and promotions.

There is a thought repeated as a mantra all the time by the marketers: "[...] our competition is very aggressive so, as a consequence, frequent new launches and a portfolio of products that offers a complete solution for the end users are mandatory to grow the business". It is difficult to take market share from other competitors. To continue growing, the strategy is increasing the portfolio of products year over year, increasing company's "vitality index". In fact, the product life cycles are being shortened to launch new generations of products with more added value and higher margins. Sales force and marketing professionals believe that all SKUs contribute with a small share for the total company revenue and the customers may order them anytime so it is important to keep the traditional portfolio while bringing innovative products.

In addition to that, special products, combos and festive packages are need in the main dates of the year associated with big promotions (e.g., father's day, Easter, Christmas, Halloween, back to school). In the average, between three and eight seasonal SKUs per product line are developed for each special date. Table 2 presents the global portfolio evolution in the last years.

Marketing and Sales teams in the subsidiaries prepare the sales forecast together every month. The local structure depends on the size of the market and the sales in each country. Sometimes a Marketing manager is responsible for more than one country. For the regular portfolio, they consider the historical data and the expected positive effects of the planned promotions, always trying to deliver the committed budget financial figures. In general, the almost 60\% forecast accuracy (total company average) that has been achieved is considered a quite reasonable result for the regular portfolio. However, they claim that new launches are "completely different animals" as it is not an easy task anticipating the market demand of new products. As there is no historical data in this cases, Marketing uses USA historical information as a basis to forecast, adjusted for the size of the local market. As one of the brand managers in USA stated: "Although the products are awesome, sometimes it takes some time to educate the market on the advantages of the new launches."

Table 2. Global portfolio evolution.

\begin{tabular}{cccccc}
\hline \multirow{2}{*}{ Year } & \multicolumn{2}{c}{$\begin{array}{c}\text { SKUS } \\
\text { Launched / Discontinued }\end{array}$} & & \multicolumn{2}{c}{ SKU Count } \\
\cline { 2 - 3 } & Hand Tools & Office Products & & Hand Tools & Office Products \\
\cline { 2 - 3 } 2013 & $700 / 23$ & $250 / 18$ & & 6858 & 1355 \\
2014 & $639 / 18$ & $350 / 14$ & & 7479 & 1691 \\
2015 & $558 / 12$ & $338 / 10$ & 8,025 & 2,019 \\
\hline
\end{tabular}




\subsubsection{Customer Service}

Customer Service is in charge of the order management, the contact with customers, the service level measurement and they support the Sales force providing information about orders, deliveries, customer complaints and returns. This function was part of Sales before but it changed when the company adopted a new organizational structure where Operations encompasses the "end to end", from bringing raw-material from suppliers to delivering finished goods to customers. Now Customer Service is part of Logistics in each subsidiary.

In Sales, the flexibility to attend the customers was tremendous, everything was an exception and everything was urgent, minimum order value and minimum order quantity are frequently disregarded. However, the service is not better than today because of that. Now in Logistics, there is a sense of urgency and some exceptions are accepted to attend customer needs, but the rules are respected in general. The service continues the same though.

The majority of the DCs are efficient; they ship fast with low level of errors. The main problem is the lack of the right inventory. A customer service representative from Brazil explained their daily challenges:

Our customers use our catalog and our product codes to build their orders. The problem is that we usually do not have product enough to fulfill an order 100\%. There are thousands of products and thousands of customers. Therefore, we need to check the customer profile or sometimes call the customer directly to decide if we ship the order now missing product or wait until we have $100 \%$ to ship. In the first case, we affect our line-fill and in the second alternative, we affect our on-time. In addition, it is hard to know when we will have the lacking product available again. If asked, we give an estimate, our best guess to the customers and they know they cannot totally rely on this information anyway. Sometimes we ship the same order in partials 3 times until we deliver 100\%. We often ship less than the minimum order if we cannot consolidate the partials with other orders from the same customer.

\subsubsection{Research and Development (R\&D)}

R\&D is a key area for the company today because the corporate strategy is "differentiation" through innovation and perceived quality by the customers. Additionally, Marketing and Sales growth strategies rely on constant new product launches and shorter life-cycles. Margins have decreased so there is expectation from the senior executives in Dallas that $R \& D$ will be able to develop new generations of innovative products with the same perceived high quality, maintaining the product performance but producing with lower manufacturing and raw-material costs.

There is good collaboration with Marketing and Manufacturing. Some plants are used to test products in real industrial environment. That is not considered the ideal situation as R\&D can make its tests only when Manufacturing can release their equipment and they do not want to stop production very often because it affects their performance indicators in pieces per hour and cost per piece. There is a project to build two pilot plants for R\&D, one for hand tools and another one for office products in two manufacturing sites but the initiative is on hold due to the high investments needed.

\subsubsection{Production}

From the Manufacturing perspective, they were traditionally the core of the business, but now it is driven by Marketing and Sales. The net of manufacturing plants has 19 facilities worldwide, which are completely independent from the local subsidiaries, reporting directly to a global manufacturing vice-president in Dallas and to the COO. They produce to all 32 subsidiaries, supplying around 5.5 thousand regular SKUs and parts of the different promotional products developed for the festive dates every year.

As one of the plant managers in Mexico explained:

We pretty much manufacture global products so we need to run big batches in order to fulfill incoming orders from different subsidiaries, asking for the same SKUs. We follow strictly a FIFO order sequence, all subsidiaries are equally important to us, and there is a two-month frozen time window without changes in the requested orders. Otherwise, we cannot plan and be efficient. We try to keep our production lines full steam ahead running with the same SKUs, reducing the set-ups. We need to keep the costs down to deliver the operations budget and continue competitive. Many inefficient plants in the company were closed. It is hard to keep our high quality standards and low costs though because we constantly receive requests to change orders previously sent and confirmed by the subsidiaries. We do our best to attend exceptions without compromising the plant results. Unfortunately, we cannot be much flexible because it disturbs our planning, execution, and production costs and reinforces their habit of asking for short notice changes. I think we could have some kind of periodic meetings with the subsidiaries for alignment. Nevertheless, there are too many... Today we receive their orders every month and often their request for changes in the orders. 
Once a year we receive their next year's forecast that we consolidate and use to plan our capacity and our supply but unfortunately, we cannot rely too much on that information. We need to complement it with our assumptions and we need to build a plan that keeps our production rates. Another issue we face here in this plant is the interruption in the production to allow $R \& D$ to test new products. After the development in the lab, they always want to test again in regular production equipment in the industrial environment. They should have a pilot plant. Although we need to face all these issues, we are proud to say that we produce excellent products for all the company worldwide.

About the new product launches, a Process Engineer in UK stated that:

Our colleagues from Sales and Marketing do not understand that depending on the new product, new machinery has to be bought and installed in a previously planned layout designed to be efficient, new processes need to be developed and tested by Engineering. There is always a learning curve. Very often we face huge challenges to develop the process to produce in industrial scale the innovative products Marketing and R\&D create. Frequently, new products are presented leaving us a very aggressive schedule to develop the process and prepare the production line, although we find out later that they had been discussing the project for months without sharing the information with us. We could give our insights, we could start planning and working earlier in the projects [...].

The planning and inventory control professionals at the subsidiaries complain about the low sales forecast accuracy. In fact, the company average forecast accuracy at an aggregate level is $58 \%$. They send the supply orders to the company plants and to global and local suppliers based on the forecast received from Sales and Marketing locally in their subsidiaries, but they always end with excess of some SKUs and lack of others in the distribution centers. They have an inventory target to deliver according to budget, but they are always above the objective because they need to rush orders and ask for more of the product that is selling, while excesses and obsoletes do not move in the warehouses. The Sales team is always complaining about the service level and blaming them for sales lost, while Finance complains about the high inventory level. From planners' perspective, nobody seems to understand or care about the forecast accuracy problem. A planner in France sharing his doubts said:

1 would like to understand how the inventory targets determined by Finance are calculated. Does Finance take in account the complexity of the company's supply chain? The number of internal and external suppliers spread in dozens of countries, thousands of SKUs and long lead-times [...].

\subsubsection{Sourcing}

Around 50\% of the finished goods portfolio and the key raw-materials are outsourced from 25 key suppliers. The most important countries from a sourcing perspective are USA, Mexico, Brazil, China, Taiwan, Japan, India, Germany, UK, and France. The Global Sourcing team at headquarters (Dallas) is responsible for identifying and developing the global suppliers and for assessing their capacity to attend the company total demand "on quantity, on spec, on cost and on time". They negotiate prices with suppliers on-behalf of the entire corporation in order to increase the bargaining power and they audit them periodically. Besides this Global Sourcing team, there is a local team in each geographic region, close to key suppliers, being their biggest organization located in China (Shanghai and Chen Zhen), where 48 people support the sourcing, procurement and quality assurance initiatives.

Global Sourcing negotiates key raw-materials for the company owned plants like for instance high-speed steel, carbon steel and wood pencil bodies. One of the sales champions the office products business has is a black pencil manufactured in a "maquila" (labor intensive low cost plant) in the especial tax area in the north of Mexico, made with a wooden body produced in China that is sold to the North American market. A very high-end pen for white boards, a product that does not sell that much but is very traditional in Europe, is also manufactured in Mexico using an aluminum cylinder body that is produced in UK. These are some examples of the sourcing complexity. The plants work together with Global Sourcing to generate an annual supply plan (raw-materials, packaging materials, components) and communicate it to the key global suppliers. Plants place orders on a monthly basis, adjusting them according to their demand and considering suppliers' lead-times. This planning process is important, especially when the global market is heated as it has happened in the recent years due to China production growth. Other not strategic raw-materials, packaging materials and supplies are acquired directly by the plants.

One of the vice presidents of a global high-speed steel supplier from Austria that supplies to the hand tools plants in Europe and to the plant in Brazil declared: "Global-Enterprises is one of our most important clients. We could be a better supplier and partner to Global-Enterprises though, if we could increase our integration. This could improve our service and reduce inefficiencies and other costs related to demand uncertainties that could be mutually beneficial. We have ongoing programs like this with other clients with very good results. Today we need to keep extra inventory just in case. Sometimes we end with inventory stopped for a long time 
without orders and sometimes, even though we had a safety stock, we cannot provide the service level GlobalEnterprises deserves."

New product launches are one of the main concerns for Global Sourcing. Usually the products are introduced with little information ahead of time, making them rush to find a good supplier of finished goods or raw-materials and to negotiate, under time pressure, competitive rates that achieve the target costs. Also, frequently, there are long make-or-buy discussions involving Global Sourcing and company plants that are interested in manufacturing the new SKUs internally in order to increase their strategic importance and receive production capacity investments.

\title{
4.2.7. Finance
}

The Finance area at the corporation headquarters is in constant communication with the local Finance team in each subsidiary, their eyes, ears and arms worldwide. Finance is, at all levels, the ultimate guardian of the budget, of the company money and its assets. The local Finance teams do not want to get much involved in the operations details and issues. They do not want to play the role of guarantors of Sales and Operations excuses for not delivering the agreed results. So a strategic distance is considered healthy to be able to judge and report impartially. At the end of the day, a plan and a budget were committed by everybody months ago, in the last year, for this year and their primary missions are making sure it is delivered or, if not possible, to report and to explain to the corporation the reasons. As the CFO occasionally used to quote: "In business there are results and excuses, but only the first ones count."

A Finance senior manager from the headquarters shared the overall area's perspective:

\begin{abstract}
Our sales are usually on plan or sometimes even better, but the forecast is not good at all. The amount of customers' orders brought is fine in value, enough to deliver the committed objective. So Sales force is satisfied, mission accomplished from their perspective but, due to service level issues, many orders are not shipped complete, reducing the revenues and increasing the logistics costs. They planned to sell product $A$ but they end up selling more of product $B$. That happens everywhere. It is even worse with new products. Marketing is always extremely optimistic in their forecasts. The portfolio is huge and many items do not sell well, but they are kept anyway just in case, increasing the slow movers' - excess and obsolete - inventory value. Who needs three different models of a general-purpose plier or five different shades of blue pencils? Besides that, it is too easy for customers to return an order they requested. Sales does not want to get their customers stressed or upset by any reason and always accept returns. In the other hand Operations is not flexible. The result: lots of inventory! The inventory destroys our cash flow and prevents us from having money to invest. Our margins and profit have decreased affecting the share value. Return-on-Assets is low in the company because of the high inventory and because of all the manufacturing plants we have all over the world. 1 do believe we should close and consolidate a good part of them and outsource much more.
\end{abstract}

Finance would rather have a leaner, less complex and more profitable business that had less assets, less inventory, lower working capital, a smaller portfolio composed by only products that really sell with healthy margins, focused on the good customers that pay well and do not return. Global presence is nice but not necessarily in all these countries. Certainly, these measures would positively affect the share value. As per Finance assessment, the new product launches frequently do not bring the planned revenues as they do not sell the amount which was initially forecasted or because their real cost ended up higher than projected due to material or manufacturing burdens and logistics costs above budget.

\subsubsection{Information Technology (1T)}

Global-Enterprises grew over the years buying other companies so there are many Enterprise Resource Planning (ERP) systems being used all over the world (SAP, Oracle, JP Edwards, MAPICS etc.) in the 32 subsidiaries and in the corporation headquarters. Even when the ERP is the same, the version may be different, the language and other variables and units used in the configuration are different, the modules installed are not the same, people are not rightly trained to use all the features the system offers, the license and maintenance contracts are independent and linked to local companies. The majority of the systems in use were customized to attend local requests. The companies that were acquired use different support systems interfaced to their ERPs, sometimes expensive programs recognized in the market and bought from big software houses, sometimes solutions developed by local software houses. There are special packages interfaced with the ERPs to handle specific needs from the countries to attend local legislation.

The corporation in USA uses the ERP from SAP, recently updated to the latest version. The Sales team and Customer Service use a Customer Relationship Management (CRM) System from SAP (MYSAP) to support their 
work and improve the communication with customers. Demand planners use Demand Solutions in the forecasting process. The plants use SAP/APO for floor planning and control. Material planners use the SAP/MRP module. All orders are sent from the sales representatives through their handhelds or come by EDl. The DC uses the Warehouse Management System (WMS) Manhattan and the Transportation Management System (TMS) OTM.

In Western Europe, subsidiaries utilize systems intensively. They are highly developed and are standardizing SAP, following USA, although satellite systems and other automation tools developed by European companies are also utilized. Besides Brazil (mostly with Oracle systems) and Mexico (a mix between MAPICS and SAP systems), the rest of the Latin America subsidiaries are not well developed from an IT perspective. In the Asia-Pac region there are huge discrepancies, some operations well developed and others not, different systems being used as well.

Today a practical implication of all these different systems running at the same time is the huge effort made in the second working day of each month, when all subsidiaries are sending their information in a specific format to allow the total company result consolidation at Dallas headquarters.

The company recently developed a pilot-study in Western Europe with the implementation of an Electronic-points of sales (EPS) program, counting with a huge investment in IT, people and changes in local processes. However, none of the European executives responsible for the program could convince the new CEO that the program was succeeding. It seemed that the company did not know how to manage the data collected in real-time daily from the thousands of sales units. Therefore, the new CEO was struggling to find a better use for this program.

\subsection{Call for proposals}

The new CEO of Global-Enterprises Inc. asked different consultancies to create an outline for a S\&OP implementation in his company. The company will base its decision to hire a consultancy firm based on the proposal that best fits its current scenario.

Students should assume the role of a consulting firm specialized in the area of Supply Chain Management. The firm's expertise in transforming enterprises has been proven in several successful projects, amongst others, introducing S\&OP. The task is to create a project proposal to pitch to the new CEO of Global-Enterprises Inc.

\section{Final remarks}

This paper offers a useful teaching and learning approach for S\&OP. A teaching case method was developed and applied to graduate students of the University of Münster. Adopting the constructive alignment principle (Biggs, 2003; Biggs \& Tang, 2011), this teaching approach aimed to provide students with the knowledge of how to overcome real-life challenges in S\&OP, contributing to improve their analytical and critical-thinking skills. Within the discipline, the students were initially prepared with theoretical background on different conceptual S\&OP building blocks. The use of the S\&OP framework offered by Thomé et al. (2012) supported this learning phase. After acquiring this knowledge, students were exposed to an industry case, reflecting a real-life scenario. They assumed the role of a consulting firm and developed a proposal with a solution to the case problem based on their knowledge on S\&OP and their understanding of the facts available in the case description. By dealing with the different building blocks of S\&OP in a real-life situation, students had to unveil business arrangements and configurations to balance the different advantages and disadvantages of possible alternatives to the problem, to evaluate the resulting tradeoffs among these alternatives, to separate major from minor issues, and finally, to make a decision.

The combination of the teaming and assistant teaching models in the conduction of the discipline was successful. First, due to the interdisciplinary perspective inherent to S\&OP, combining professors from different fields (i.e., Industrial Engineering and Information Systems) enriched the class discussions with distinct perspectives and analyses. The support from the assistants aided in supplementing and complementing the theoretical and practical discussions. The teaching assistants functioned as facilitators and played an important role in the discipline. They provided follow-up activities in different conceptual topics and practical issues related to the case, which helped to mitigate difficulties faced by the students in finding a solution. This use of facilitators and their importance in case methods is aligned with the literature (e.g., Srinivasan et al., 2007; Thistlethwaite et al., 2012). The participation of the executive from the case company led to an esteeming enthusiasm with the students and brought a real-life atmosphere to the classroom. The executive's feedback to the students' case solution was also important, not only regarding motivational aspects, but it also revealed additional insights regarding the scenarios and solutions faced by the company in real-life.

The faculty members' perception of the learning outcomes obtained with the case method was positive, corroborating Lundeberg \& Yadav (2006) and Prince \& Felder (2007). Formal and informal feedbacks from 
students and the involved executive in different stages along the semester were also positive. Relationships between students, teachers, discipline characteristics and SET scores were analyzed (i.e., Spooren et al., 2013). Students' attitudes, like their engagement in the discipline (inside the classroom as well as outside), were considered higher than in other disciplines with traditional lecture-based education. Although their effort and time dedication was higher, the challenging environment and the reduction of the distance between the teaching activity and the practical reality motivated the students in this learning approach, corroborating Spooren et al. (2013). The interest and motivation shown by the students was demonstrated by the increased class attendance, an outcome equally observed by Lundeberg \& Yadav (2006), and Spooren et al. (2013). This observation was reinforced in the SET's open-ended and closed-ended questions regarding the students' satisfaction with the teaching quality and learning experience. The constant evaluation along the semester was also important in this learning experience. At the beginning, students were reluctant in facing a real-life case in a subject in which they had limited knowledge. The experience from the discipline showed that the second phase regarding the practical case analysis could only start after students had built up their theoretic knowledge obtained in phase 1. Once this theoretical background was obtained, students felt comfortable to face the real-life problems in the teaching case. The discipline evaluation also revealed that students not only improved their knowledge on S\&OP, but also improved their analytical and critical-thinking skills, corroborating the literature on case methods as an important instructional technique.

This study contributes to the theory of teaching methods by corroborating early findings regarding enhanced learning experience provided by the teaching case method, as noticed earlier by Hackney et al. (2003), Kim et al. (2006), Srinivasan et al. (2007), and Thistlethwaite et al. (2012). The teaching case equally resulted in pre-formatted materials, guidelines, and evaluation guides for classroom practices in S\&OP, without loss of generality. These teaching guidelines might equally be applied to other management practices to be taught in Master of Sciences classroom settings in engineering. Based on the successful application of the discipline at the University of Münster, this case method in S\&OP is now being reproduced in different universities in Germany and abroad. The success in obtaining the learning objectives observed within this German experience reinforces that the case method approach should be more intensely used in Engineering education.

\section{References}

Baeten, M., \& Simons, M. (2014). Student teachers' team teaching: models, effects, and conditions for implementation. Teaching and Teacher Education, 41, 92-110. http://dx.doi.org/10.1016/j.tate.2014.03.010.

Barnett, C. (1998). Mathematics teaching cases as a catalyst for informed strategic inquiry. Teaching and Teacher Education, 14(1), 81-93. http://dx.doi.org/10.1016/S0742-051X(97)00062-0.

Biggs, J. (2003). Teaching for quality learning at university: what the student does. Buckingham: SRHE and Open University Press.

Biggs, J., \& Tang, C. (2011). Teaching for quality learning at university. Maidenhead: McGraw-Hill and Open University Press.

Buckley, F. J. (1999). Team teaching: what, why, and how? Thousand Oaks: SAGE Publications.

Cox, J. F., \& Blackstone, J. H. (2002), APICS Dictionary (10th ed.). Alexandria: APICS.

Edström, K. (2008). Doing course evaluation as if learning matters most. Higher Education Research \& Development, 27(2), 95-106. http://dx.doi.org/10.1080/07294360701805234.

Elbaum, S. (2004). Dynamic sales and operations planning: the next generation solution to a dynamic marketplace. Boston: Aberdeen Group.

Farhoomand, A. (2004). Writing teaching cases: a reference guide. Communications of the Association for Information Systems, 13, 103-107. Retrieved in 9 April 2016, from http://aisel.aisnet.org/cais/vol13/iss1/9

Godsell, J., Birtwistle, A., \& Van Hoek, R. (2010). Building the supply chain to enable business alignment: lessons from British American Tobacco (BAT). Supply Chain Management: An International Journal, 15(1), 10-15. http://dx.doi.org/10.1108/13598541011018085.

Goh, S. H., \& Eldridge, S. (2015). New product introduction and supplier integration in sales and operations planning. International Journal of Physical Distribution \& Logistics Management, 45(9-10), 861-886. http://dx.doi.org/10.1108/1JPDLM-08-2014-0215.

Grimson, J. A., \& Pyke, D. F. (2007). Sales and operations planning: an exploratory study and framework. International Journal of Logistics Management, 18(3), 322-346. http://dx.doi.org/10.1108/09574090710835093.

Hackney, R., McMaster, T., \& Harris, A. (2003). Using cases as a teaching tool in IS education. Journal of Information Systems Education, 4(3), 229-234.

Hollmann, R. L., Scavarda, L. F., \& Thomé, A. M. T. (2015). Collaborative planning, forecasting and replenishment: a literature review. International Journal of Productivity and Performance Management, 64(7), 971-993. http://dx.doi.org/10.1108/IJPPM-03-2014-0039.

Hulthen, H., Näslund, D., \& Norrman, A. (2016). Framework for measuring performance of the sales and operations planning process. International Journal of Physical Distribution \& Logistics Management, 46(9), 809-835. http://dx.doi.org/10.1108/IJPDLM-05-2016-0139.

Kim, S., Phillips, W. R., Pinsky, L., Brock, D., Phillips, K., \& Keary, J. (2006). A conceptual framework for developing teaching cases: a review and synthesis of the literature across disciplines. Medical Education, 40(9), 867-876. PMid:16925637. http://dx.doi. org/10.1111/j.1365-2929.2006.02544.x. 
Kjellsdotter lvert, L. K., Dukovska-Popovska, 1., Kaipia, R., Fredriksson, A., Dreyer, H. C., Johansson, M., Chabada, L., Damgaard, C., \& Tuomikangas, N. (2015a). Sales and operations planning: responding to the needs of industrial food producers. Production Planning and Control, 26, 280-295. http://dx.doi.org/10.1080/09537287.2014.897769.

Kjellsdotter lvert, L. K., Dukovska-Popovska, l., Fredriksson, A., Dreyer, H. C., \& Kaipia, R. (2015b). Contingency between S \& OP design and planning environment. International Journal of Physical Distribution \& Logistics Management, 45(8), 747-773. http://dx.doi. org/10.1108/1JPDLM-04-2014-0088.

Kjellsdotter lvert, L. K., \& Jonsson, P. (2014). When should advanced planning and scheduling systems be used in sales and operations planning? International Journal of Operations \& Production Management, 34(10), 1338-1362. http://dx.doi.org/10.1108/ IJOPM-03-2011-0088.

Lapide, L. (2005). Sales and operations planning. Part 111: a diagnostic model. The Journal of Business Forecasting, 24(1), 13-16.

Levin, B. B. (1995). Using the case method in teacher education: the role of discussion and experience in teachers' thinking about cases. Teaching and Teacher Education, 11(1), 63-79. http://dx.doi.org/10.1016/0742-051X(94)00013-V.

Lundeberg, M. A., \& Yadav, A. (2006). Assessment of case study teaching: where do we go from here? Part 11. Journal of College Science Teaching, 35(6), 8.

Mendes Junior, P. M., Leal, J. E., \& Thomé, A. M. T. (2016). A maturity model for demand-driven supply chains in the consumer product goods industry. International Journal of Production Economics, 179, 153-165. http://dx.doi.org/10.1016/j.ijpe.2016.06.004.

Noroozi, S., \& Wikner, J. (2017). Sales and operations planning in the process industry: a literature review. International Journal of Production Economics, 188, 139-155. http://dx.doi.org/10.1016/j.ijpe.2017.03.006.

Prince, M., \& Felder, R. (2007). The many faces of inductive teaching and learning. Journal of College Science Teaching, $36(5), 14$.

Rexhausen, D., Pibernik, R., \& Kaiser, G. (2012). Customer facing supply chain practices: the impact of demand and distribution management on supply chain success. Journal of Operations Management, 30(4), 269-281. http://dx.doi.org/10.1016/j.jom.2012.02.001.

Sousa, R. S., \& Voss, C. A. (2008). Contingency research in operations management practices. Journal of Operations Management, 26(6), 697-713. http://dx.doi.org/10.1016/j.jom.2008.06.001.

Spooren, P., Brockx, B., \& Mortelmans, D. (2013). On the validity of student evaluation of teaching: the state of the art. Review of Educational Research, 83(4), 598-642. http://dx.doi.org/10.3102/0034654313496870.

Spooren, P., Mortelmans, D., \& Denekens, J. (2007). Student evaluation of teaching quality in higher education. Development of an instrument based on 10 Likert scales. Assessment \& Evaluation in Higher Education, 32(6), 667-679. http://dx.doi. org/10.1080/02602930601117191.

Srinivasan, M., Wilkes, M., Stevenson, F., Nguyen, T., \& Slavin, S. (2007). Comparing problem-based learning with case-based learning: effects of a major curricular shift at two institutions. Academic Medicine, 82(1), 74-82. PMid:17198294. http://dx.doi.org/10.1097/01. ACM.0000249963.93776.aa.

Thistlethwaite, J. E., Davies, D., Ekeocha, S., Kidd, J. M., MacDougall, C., Matthews, P., Purkis, J., \& Clay, D. (2012). The effectiveness of case-based learning in health professional education: a BEME systematic review: BEME Guide No. 23. Medical Teacher, 34(6), 421-444. PMid:22578051. http://dx.doi.org/10.3109/0142159X.2012.680939.

Thomé, A. M. T., Hollmann, R. L., \& Scavarda, L. F. (2014). Research synthesis in collaborative planning forecast and replenishment. Industrial Management \& Data Systems, 114(6), 949-965. http://dx.doi.org/10.1108/IMDS-03-2014-0085.

Thomé, A. M. T., Scavarda, L. F., Fernandez, N. S., \& Scavarda, A. J. (2012). Sales and operations planning: a research synthesis. International Journal of Production Economics, 138(1), 1-13. http://dx.doi.org/10.1016/j.jpe.2011.11.027.

Tuomikangas, N., \& Kaipia, R. (2014). A coordination framework for sales and operations planning (S\&OP): synthesis from the literature. International Journal of Production Economics, 154, 243-262. http://dx.doi.org/10.1016/j.jpe.2014.04.026.

Voss, C., Tsikriktsis, N., \& Frohlich, M. (2002). Case research in operations management. International Journal of Operations \& Production Management, 22(2), 195-219. http://dx.doi.org/10.1108/01443570210414329.

Wagner, S. M., Ullrich, K. K., \& Transchel, S. (2014). The game plan for aligning the organization. Business Horizons, 57(2), $189-201$. http://dx.doi.org/10.1016/j.bushor.2013.11.002.

Received: Apr. 9, 2016

Accepted: Apr. 22, 2017 
Appendix A. Teaching guide.

Synopsis of the case: Global Enterprises Inc. is a multinational corporation headquartered in Dallas present in more than 30 countries, which employs 12,000 people and manufacturers and commercializes globally a wide variety of consumer goods of recognized brands. The company is facing problems that affect its performance in the market and the share value has decreased in the past two years. The trend concerns the board as shareholders are dissatisfied and may decide to invest in businesses that are more attractive. In addition, the current share value puts the corporation in a vulnerable position at risk of being acquired by a competitor in an aggressive movement in the Wall Street stock market. To face these problems, the company has recently hired a new CEO. His primarily mission is growing the business and increasing the share value, putting the company back on track and leading it to a bright future. The CEO realized that the company's main problems, which are preventing the business from being successful, are mainly internal. Most of them can be traced back to operational problems, lack of internal coordination and poor planning processes. In his former company, the CEO experienced the implementation of an S\&OP process. Although the process was not completely mature yet, he was able to verify fast improvements in the company and very promising early results. The CEO does believe it is possible to improve the service level, diminish the inventory and increase the working capital and profit, all at the same time.

Target Audience: The intended audience are students from industrial engineering, information systems and business management courses, as well as practitioners in specific workshops on S\&OP (in-company or in a university).

Learning objectives: To provide students with the knowledge of how to overcome practical challenges by applying the main building blocks of S\&OP in a real-life situation, contributing to improve their analytical and critical-thinking skills.

Teaching plan: It consists of two parts. A first to provide students with an understanding of the main S\&OP elements based on Thomé et al. (2012) framework (see Section 2). Students should choose one or two conceptual building blocks and develop an essay based on the academic and gray related literature. Continuous feedback on the evolution is provided in regular meetings with facilitators. Essays are presented to all students for further group discussions and knowledge share. The second part regards to the case analysis, using the previous knowledge on S\&OP as a starting point. Students are organized in groups to develop a solution from a teamwork perspective.

Guidelines for the presentation of the case's solution: Students should prepare a presentation of 30 minutes with the case solution of their group. The presentation should summarize the current state of the company and the project plan towards a S\&OP implementation (or not). The following points should help students in structuring their presentation: (i) As-ls situation of the company's organization and processes, (ii) Identified problems and their relation to a S\&OP solution, (iii) To-Be state after the successful implementation of S\&OP including the maturity level, supply chain integration degree, process sketch of the S\&OP cycle, costs and benefits analysis, and (iv) Road map the S\&OP introduction including milestones (e.g., before, during and after go life) and work packages. 